\title{
Using Peer Review in a Freshman Engineering Graphics Course to Enhance Understanding of Basic Dimensioning Techniques
}

Dr. Nancy E. Study, Pennsylvania State University, Erie

Nancy E. Study is on the faculty of the School of Engineering at Penn State Erie - The Behrend College where she teaches courses in engineering graphics and rapid prototyping, and is the coordinator of the rapid prototyping lab. Her research interests include visualization and haptics. She is a former chair of the ASEE Engineering Design Graphics Division and is currently the Circulation Manager and Treasurer of the Engineering Design Graphics Journal. 


\section{Using Peer Review in a Freshman Engineering Graphics Course to Enhance Understanding of Basic Dimensioning Techniques}

Introduction

Appropriate application of basic dimensioning techniques is a topic that students enrolled in an introductory engineering graphics course have problems with on an ongoing basis. Errors that occur regularly on assignments and exams, despite instruction, assignments, and required reading on the topic, include poor or incorrect placement, missing dimensions, over dimensioning, and incorrect formatting. Problems with dimensioning are not unique to this course as has been indicated in other research ${ }^{1,2,3}$.

In an attempt to improve students' dimensioning techniques and reinforce the importance of being able to read drawings that others have created, peer review of select assignments was introduced into the course during the Fall 2014 semester. In previous semesters, drawings were graded solely by the instructor and returned to the students with specific feedback. General comments were made to the class at large on what students were typically getting correct and incorrect on the assignments, and occasionally individual students would ask for more detailed feedback on their work but this was the exception more than the rule.

As part of the new peer assessment plan, students handed a print of the multiview drawing in to the instructor at the beginning of lab then the assignments were redistributed to the students so they could assess the drawings and mark any errors. Correctly identifying the majority of the errors on the drawing they marked up was part of each student's grade. Actual grading and assigning point values to the errors was not part of the peer review, this was done by the instructor.

Grades on the individual assignments along with final project and exam scores were compared to those from previous semesters. Grades on the individual assignments improved significantly but there were no significant differences in the exam grades or overall grades. This may be due, in part, to the relatively small portion of the overall possible points in the semester that the dimensioning exercises and exam questions comprised.

Course Description

EGT 120 - Introduction to Graphics and Solid Modeling, is a required course for freshman-level students in several engineering technology associate and baccalaureate degree programs in the School of Engineering at Penn State Erie. It is also required for some business students who are enrolled in an interdisciplinary business with engineering studies program. The course focuses on the development of visualization skills, and creating and dimensioning orthographic and isometric representations of mechanical parts. There is one fifty minute lecture each week, along with two one hour and fifty minute lab periods. 
During the 15 week semester, the first five weeks contain no CAD work and coursework focuses on sketching techniques, multiview projection, isometric views, and dimensioning. The rest of the semester includes both sketching and CAD work and covers additional topics of auxiliary and section views, extrusions and revolutions, sweeps, detail drawings, and assemblies. At the end of the semester the students are required to submit a final project that includes an exploded assembly and a full set of detail drawings. An example of the exploded assembly drawing (Figure 1) and a page of detail drawings (Figure 2) from the Fall 14 final project are shown below.

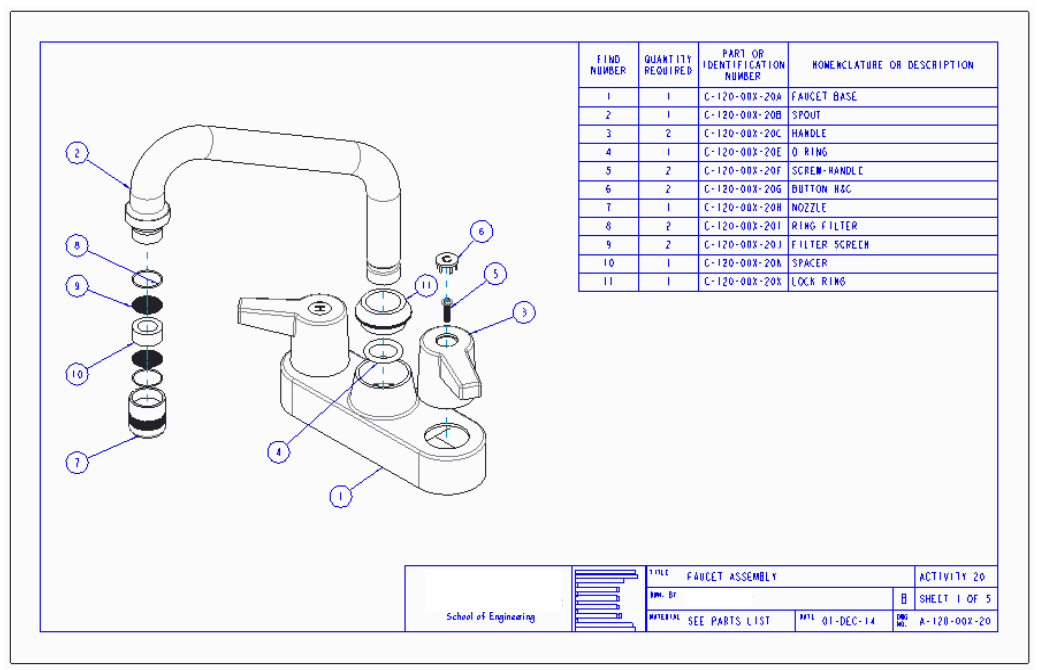

Figure 1 - Final project exploded assembly

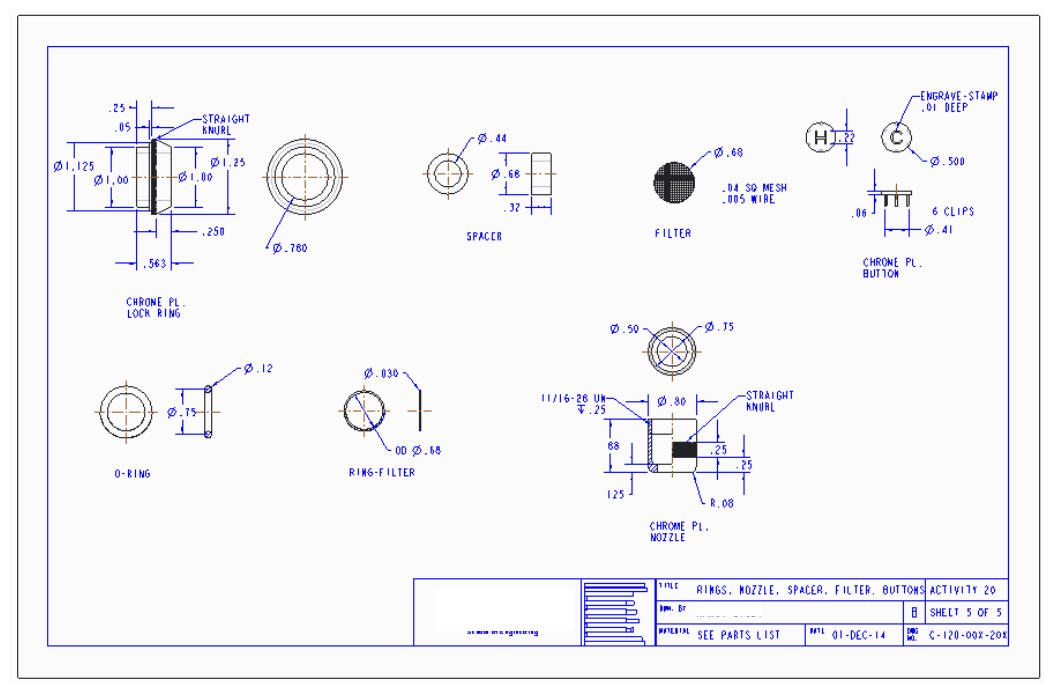

Figure 2 - Final project detail drawings

Dimensioning Instruction

The topic of dimensioning is first introduced during the fourth week of the semester via lecture and required reading from the textbook. For the first dimensioning assignment, multiview sketches of four different objects must be completed before lab, then the views are dimensioned 
during the lab period. Active student participation in the course is required so on a voluntary basis, dimensioned sketches completed by the students during class are placed on a document camera for the entire class to observe and critique. Students are given the opportunity to correct any errors in their own work before turning it in. More sketches to be fully dimensioned are assigned at the end of that lab period, completed outside of class, and then turned in at the beginning of the next lab.

In the initial instruction on dimensioning, there was no peer review in either semester aside from the aforementioned limited in-class discussion of dimensioned sketches, and all of these dimensioning assignments were graded solely by the instructor. A written exam at the end of week five contained true/false and multiple choice questions about the topics that had previously been addressed in class including dimensioning. The exam also had a completed multiview drawing that was to be fully dimensioned by the students. Questions pertaining to dimensioning related topics were approximately $30 \%$ of the possible points that exam.

The mean score on this exam in Fall 13 was 68.04 and in Fall 14 it was 66.59. A t-test indicated no significant difference with a P-value of 0.37 (Table 2). There were multiple versions of each exam, one for each of four sections in both the Fall 13 and Fall 14 semesters, but there was not a significant difference in the scores between sections. There were no major differences in how the instruction on dimensioning was accomplished through week five of both of the semesters in the study and as such, a difference in these exam scores was not expected.

During week 11, after five weeks of instruction on parametric modeling techniques such as extrusions, revolutions, sweeps, hole creation, design intent, and modeling strategies, the topic of creating detail drawings from CAD models is introduced. At this time, students are given a quick review of dimensioning standards, first discussed in week 4. It is suggested that they revisit their previous dimensioning sketching assignments that had been returned graded, along with rereading the appropriate chapters in the text and handouts on the CMS.

For the first CAD detail drawing assignment, students are required to build a model and create a detail drawing of the part shown in Figure 3. This specific assignment, and all those used in the study, were completed in both the Fall 13 and Fall 14 semesters and were from the textbook Fundamentals of Graphics Communication by Bertoline, et. al. ${ }^{4}$.

Peer review

In order to help students improve both their dimensioning techniques and their ability to read drawings, along with encouraging them to look more critically at their own work before deeming it complete, peer review was introduced into the course in the Fall 14 semester. Starting in week 11 , students turned a print of a detail drawing in to the instructor at the beginning of lab on the day it was due. The assignments were shuffled and randomly handed back to students so they would not be assessing their own work nor the work of a friend who always sits beside them in class. 
A copy of the correctly dimensioned drawing was projected on the screen in front of the lab and on the students' computer monitors along with a list of things to look for including: dimension text and arrow size, centerline use, extension line gap, correct use of diameter and radius, placement, missing dimensions, over dimensioning, and any other specific dimensioning and note requirements for the assignment. Students were allowed a limited amount of time, approximately 10 minutes, to analyze the drawing they had been given, mark any errors they found, and ask questions of the instructor on whether an alternate dimension placement, format, or method was acceptable or not.

Since part of each student's grade on their own assignment was determined by how well they marked up the drawing they were given, they lettered their name or initials on the drawing to indicate they were the person who marked it up. These initials were blanked out by the instructor before the graded assignments were returned to the class. Students reviewed the drawings for dimensioning errors only and did not assign point values to any errors they found. The instructor graded each drawing based on a standard rubric and not only marked for dimensioning mistakes, but for modeling, drawing, line, view, format, and titleblock errors also. To ensure uniformity in grading, the rubric for the Fall 14 semester was the same one used in previous semesters and students were aware of this rubric. Since neither point values nor specific grades were assigned by the students while doing the peer review, unless they shared their work with their classmates after receiving the fully graded assignment back, the peer review process did not create any grade-related privacy issues. This procedure was used for all peer reviewed assignments.

The mean score for the first Fall 14 peer reviewed detail drawing project was 7.68 compared to 7.42 for Fall 13. A t-test showed there was no significant difference in the scores with a P-value of .45 (Table 1). This was not unexpected because there had been no difference in instruction or grading procedure up to that point.

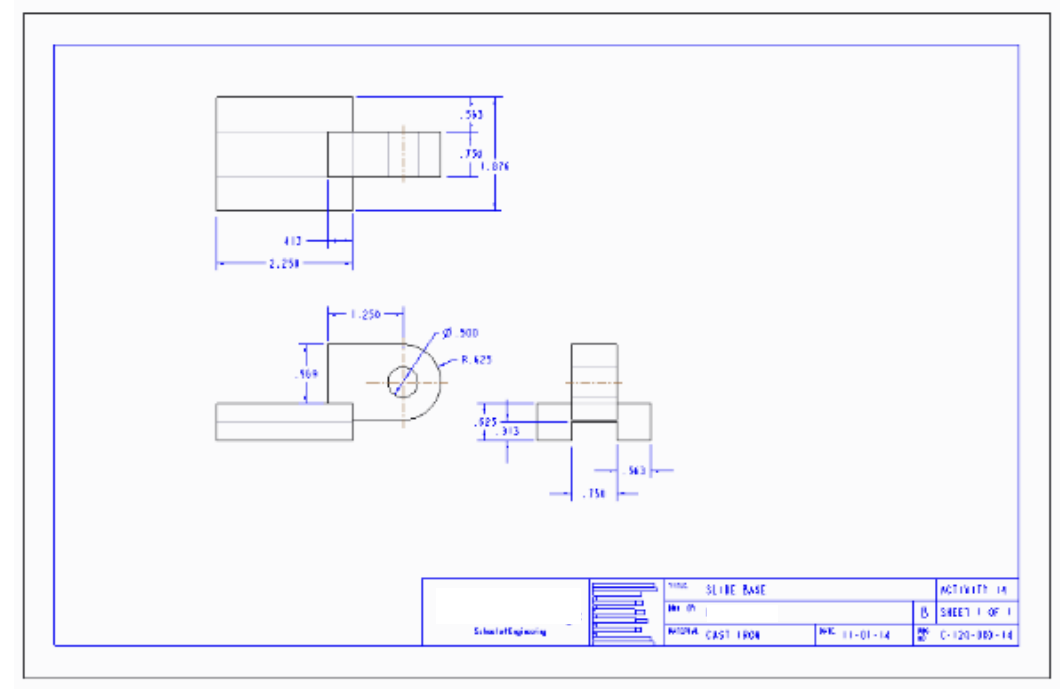

Figure 3 - Peer review assignment 1 
The second assignment that was peer reviewed was the first CAD detail drawing that required students to create an auxiliary view (Figure 4). Prior to creating the CAD model and detail drawing there was a lecture on auxiliary views, reading was assigned from the text, and an assignment with multiple auxiliary view sketches was completed. There was also a demo on how to create auxiliary views using the CAD software. The mean score for this second assignment in Fall 14 was higher than in Fall 13, 7.58 compared to 6.83. A t-test indicated this difference was significant with a P-value of .02 (Table 1).

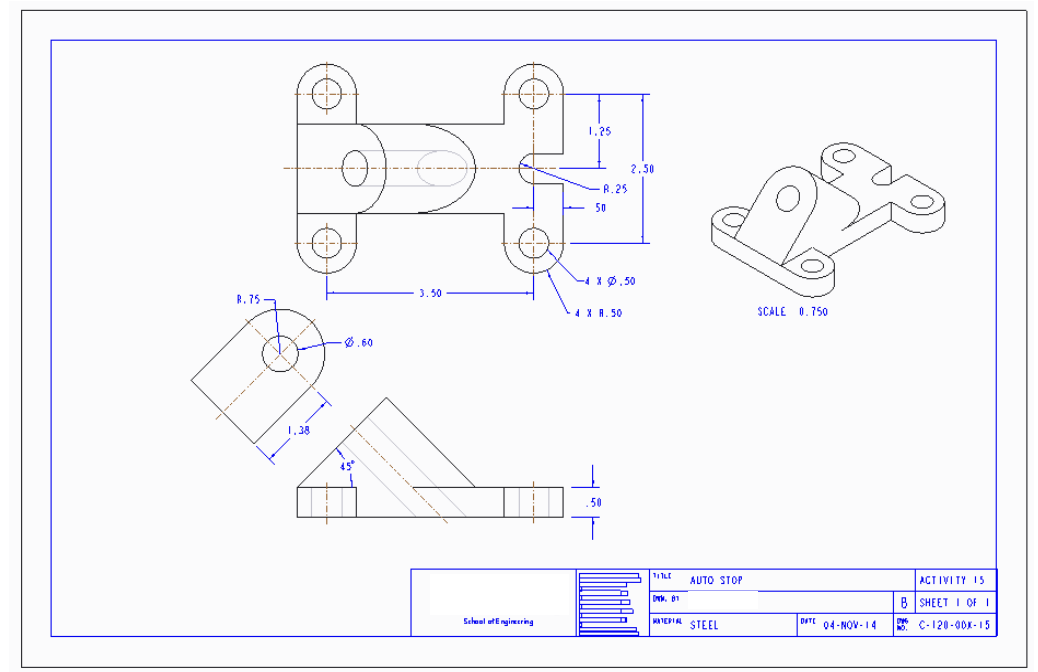

Figure 4 - Peer review assignment 2

The third peer reviewed assignment was a detail drawing of a part with a front view in full section (Figure 5). Before creating the model, students had received a lecture on section views, were assigned reading from the text, and completed sketching exercises of full, half, offset, and aligned sections. A demo on the creation of section views using the CAD software was also given. The mean score on the dimensioned section views from Fall 14 was 7.93. This was significantly higher than the Fall 13 mean score of 7.30, with a t-test yielding a P-value of .05 (Table 1).

The fourth peer reviewed assignment was a detail drawing that included an offset section (Figure 6). Before completing the model and detail drawing, there was a CAD demo on the creation of offset sections. The mean score on this drawing for the Fall 14 course was 8.05 and the score from Fall 13 was 7.07. Again, a t-test indicated the difference was significant with a P-value of .002 (Table 1). 


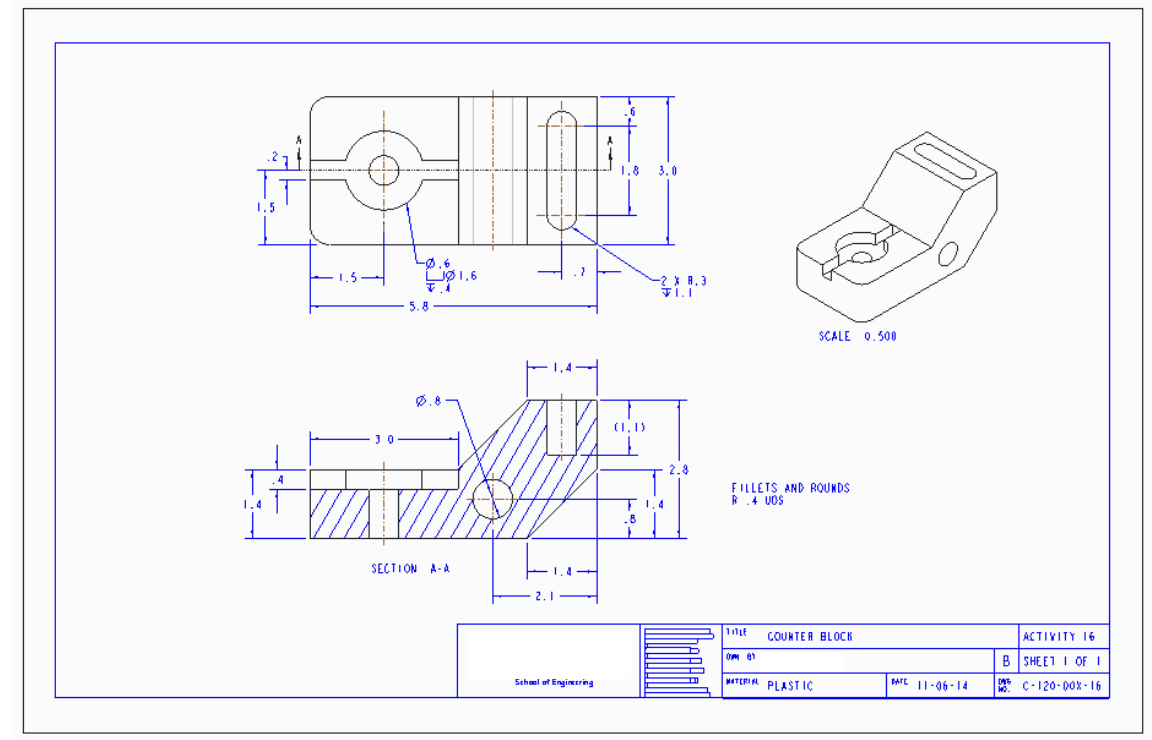

Figure 5 - Peer review assignment 3

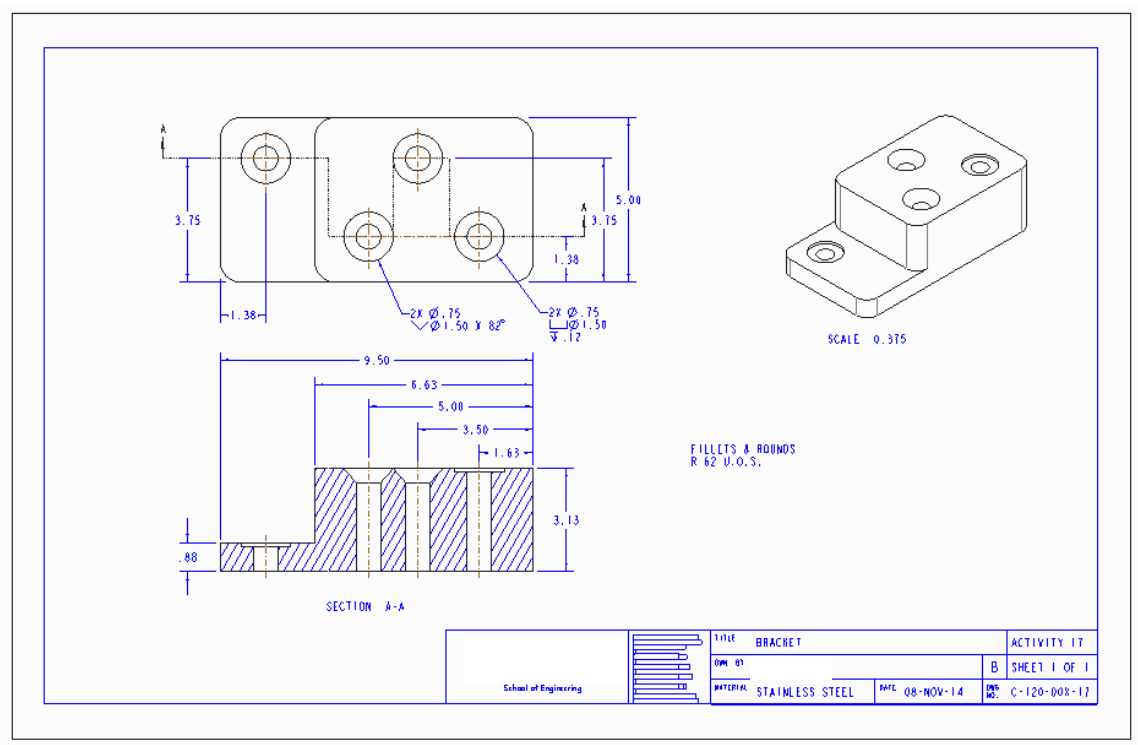

Figure 6 - Peer review assignment 4

\section{Analysis}

T-tests were used to assess the differences between the Fall 13 and Fall 14 assignment scores. Each assignment was worth 10 points and was graded with a standard rubric. A total of 83 students in the Fall 13 semester and 84 students in the Fall 14 semester completed all four assignments. Descriptive statistics indicated a negative skewness of approximately 1.5 for all variables regardless of semester or assignment. However, having distributions that are all skewed in the same direction does not violate the assumptions of the t-test. 
The four peer reviewed assignments only amounted to approximately $4.5 \%$ of the overall course grade so even with those grades being higher after peer review, the impact on the overall grades shown in Table 2 would likely be minimal. An item of interest was that across all assignments for both semesters, there was higher variance in the non-peer reviewed items than in the peer reviewed.

\begin{tabular}{|c|c|c|c|c|}
\hline \multicolumn{5}{|c|}{ T-test } \\
\hline & $\mathrm{N}$ & Mean & Std dev & P-Value \\
\hline \multicolumn{5}{|c|}{ Assignment 1} \\
\hline Fall 13 & 83 & 7.42 & 2.65 & \multirow[b]{2}{*}{0.45} \\
\hline Fall 14 & 84 & 7.68 & 1.63 & \\
\hline \multicolumn{5}{|c|}{ Assignment 2} \\
\hline Fall 13 & 83 & 6.83 & 2.61 & \multirow[b]{2}{*}{0.02} \\
\hline Fall 14 & 84 & 7.58 & 1.41 & \\
\hline \multicolumn{5}{|c|}{ Assignment 3} \\
\hline Fall 13 & 83 & 7.30 & 2.52 & \multirow[b]{2}{*}{0.05} \\
\hline Fall 14 & 84 & 7.93 & 1.45 & \\
\hline \multicolumn{5}{|c|}{ Assignment 4} \\
\hline Fall 13 & 83 & 7.07 & 2.39 & \multirow[b]{2}{*}{0.002} \\
\hline Fall 14 & 84 & 8.05 & 1.50 & \\
\hline
\end{tabular}

Table 1 - Peer reviewed assignment t-tests

There was no difference in the overall scores on the first written exam, shown as Test 1 in Table 2 , which was expected since the instruction in the five weeks preceding the exam was the same in both semesters. Grades of every student taking the first exam, regardless of whether they had completed all of the dimensioning sketches or not, were included in the statistics. As noted previously, there was a different version of the exam for each course section, but there was not a significant difference in the scores across sections in either semester.

There were no significant differences when comparing the final exam grades between the Fall 13 and Fall 14 semesters (Table 2). At this time, individual questions specific to dimensioning have not been analyzed on either the first test or the final exam, only overall exam grades. The Fall 14 final exam was substantially changed in format and included more sketching items such as missing line, missing view, isometric, auxiliary, and section views than were included in the Fall 13 exam. Even with the change in format, on both semester's final exams dimensioning was approximately $20 \%$ of the exam points and included true/false, multiple choice, and sketching questions on the topic. The grades of everyone who took the final exam were included in the statistics, even those students who did not complete all four peer reviewed dimensioning assignments. 
The final project in Fall 14 was a completely different assembly though of similar difficulty to the one in Fall 13. Students were required to make individual part models, a properly constrained exploded assembly, and a full set of working drawings. Examples are shown previously in Figures 1 and 2. For both semesters, dimensioning of the working drawings was approximately $20 \%$ of the final project grade. The grades of all students who turned in a final project were included in the statistics, even those students who did not complete all peer reviewed assignments. It is interesting to note that the variance in the Fall 13 final project grades was much greater than in Fall 14.

\begin{tabular}{|c|c|c|c|c|}
\hline \multicolumn{5}{|c|}{ T-test } \\
\hline & $\mathrm{N}$ & Mean & Std dev & P-Value \\
\hline \multicolumn{5}{|l|}{ Test 1} \\
\hline Fall 13 & 90 & 66.59 & 11.13 & \multirow[b]{2}{*}{0.37} \\
\hline Fall 14 & 90 & 68.04 & 10.52 & \\
\hline \multicolumn{5}{|l|}{ Final Exam } \\
\hline Fall 13 & 84 & 78.72 & 7.38 & \multirow[b]{2}{*}{0.16} \\
\hline Fall 14 & 83 & 77.15 & 6.95 & \\
\hline \multicolumn{5}{|l|}{ Final Project } \\
\hline Fall 13 & 84 & 78.99 & 20.68 & \multirow[b]{2}{*}{0.32} \\
\hline Fall 14 & 83 & 81.54 & 10.89 & \\
\hline \multicolumn{5}{|l|}{ Course Grade } \\
\hline Fall 13 & 85 & 75.30 & 12.58 & \multirow[b]{2}{*}{0.12} \\
\hline Fall 14 & 86 & 78.11 & 10.85 & \\
\hline
\end{tabular}

Table 2 - Exam, project, and course grade t-tests

\section{Discussion}

In this study, four assignments were peer reviewed and the sum total of possible points on these assignments amounted to less than $4.5 \%$ of the overall course grade. The improvement in grades on each peer reviewed assignment, while statistically significant, was only a gain of between one and two points out of ten in a semester that had over a thousand possible points to earn, therefore little overall impact could be expected solely from those improvements. While the total points on the final project and final exam combined were approximately $30 \%$ of the overall course grade, the portion of points on both that were specific to dimensioning amounted to around $6 \%$ of the total possible points in the course. Any potential impact the students' improved dimensioning techniques may have had on their overall course grade would likely be minimal. To gain a better overall understanding of any potential impact on the final project, final exam, and overall course grades, the dimensioning portion of the projects and exam questions specifically pertaining to dimensioning will be analyzed for significant differences when time allows. It is noted that while 
not statistically significant, the final project and overall course grades were higher in Fall 14 by 2.64 and 2.81 percent respectively.

The students seemed to take the peer review process of marking up drawings quite seriously. Many of them took time to write out notes and comments, often repeating specific information/terminology that had been used by the instructor and in the book about the errors they found. Anecdotal evidence based on questions asked of students during lab indicated that having a peer grade their assignments made them focus a little more on their work and put additional effort into understanding the necessity of dimensioning rules. Student comments during the review sessions included:

"It's hard to figure out what someone else was thinking on their drawing when its dimensions are different than mine."

"Why is it easier to find someone else's mistakes than it is to find mine before I turn it in?"

"I made the same mistakes as [student whose drawing he was marking] did. Guess I need to pay more attention."

"It's easier to grade the ones that are done right."

"This is helping me look at my own drawings more critically."

[Comment to a classmate] "Maybe we should look at each other's work before we turn it in to see if we can find mistakes first before someone else does."

When asked if they thought the peer review was helping them and if they saw improvement in their own work and that of their classmates over time, comments were generally positive and confirmed the improvement indicated by the scores. And some unsolicited, but entertaining nonetheless, comments included:

"Grading is hard!"

"How do you ever get anything done besides grading?"

"I'm never again going to ask you the next day after an assignment is turned in whether you're done grading yet. You have, what, a hundred of these to grade? And if you even spend like five minutes on each one, that's hours and hours of grading!"

It should be reiterated that although the students use the term "grading" in their comments, they did not do any of the actual grading nor did they assign point values to mistakes they found. All grading was done solely by the instructor.

It is possible that some of the influence on the improved dimensioning assignment grades could be related to observation bias with the students wishing to improve their dimensioning skills 
simply because their work is not just being assessed by their instructor, but by their fellow students. Past results that used standard methodology to grade the dimensioned detail drawings did not result in improving dimensioning skills to the desired level, perhaps because the only one routinely seeing the mistakes were the instructor and student. The peer review may have introduced an element of peer pressure resulting in students not wanting to have their work assessed unfavorably by a classmate.

That said, students in this course are required to routinely share their work with the rest of the class beginning the first week of the semester. Sketches completed as homeworks are sometimes placed on the document camera for analysis before being turned in and graded. Other times a grid is projected onto the white board and volunteers sketch the answers to multiview, missing line, missing view, and iso drawings. After the sketch is completed by the student they sit back down and there is a discussion about if it is correct, and if not, what needs to be fixed. It is emphasized to the students from day one that everyone makes mistakes, rudeness will not be tolerated, and sooner or later everyone has to get up in front of the class and have their work critiqued by the entire class.

Despite the lack of impact on overall grades, peer review will continue to be implemented, and perhaps expanded to other assignments, in future offerings of the course based on the differences in the individual assignment grades and on student feedback. There are several additional changes being considered for the course in future semesters but these are primarily related to software and also a plan to have students complete CAD tutorials outside of class time in preparation for lab exercises instead of dedicating course time specifically to CAD instruction. Course content and topics covered will remain the same and the use of sketching to introduce multiview projection, dimensioning, and other concepts will continue.

\section{References}

1. Bueno, L. A. (2014). Milestones as a guide to drafting project to improve the application of dimensioning specifications. Proceedings of the 2014 ASEE Annual Conference \& Exposition. Indianapolis, IN.

2. Veurink, N. L., and Hein, G. L. (2014). Modifying an assembly project to improve student dimensioning skills. Proceedings of the 2014 ASEE Annual Conference \& Exposition. Indianapolis, IN.

3. Devine, K.L. (2012). Dimensional tolerances: back to basics. Proceedings of the $66^{\text {th }}$ Engineering Design Graphics Division Midyear Meeting. Galveston, TX.

4. Bertoline, G. R., Wiebe, E. N., Hartman, N. W., and Ross, W. A. (2011). Fundamentals of graphics

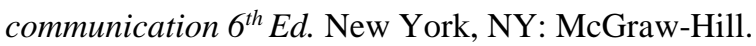

